\title{
Virginie Durand, Claude Ghiati, Isabelle Havelange et Brigitte Keriven, Bibliographie annuelle de l'histoire de France du vie siècle à 1958 - Année 2006
}

\section{Bernard Merdrignac}

\section{(2) OpenEdition}

\section{Édition électronique}

URL : http://journals.openedition.org/abpo/315

DOI : $10.4000 / a b p o .315$

ISBN : 978-2-7535-1511-6

ISSN : $2108-6443$

\section{Éditeur}

Presses universitaires de Rennes

Édition imprimée

Date de publication : 30 septembre 2008

Pagination : 209-210

ISBN : 978-2-7535-0772-2

ISSN : 0399-0826

\section{Référence électronique}

Bernard Merdrignac, «Virginie Durand, Claude Ghiati, Isabelle Havelange et Brigitte Keriven,

Bibliographie annuelle de l'histoire de France du ve siècle à 1958 - Année 2006 », Annales de Bretagne et des Pays de l'Ouest [En ligne], 115-3 | 2008, mis en ligne le 30 septembre 2008, consulté le 23

septembre 2020. URL : http://journals.openedition.org/abpo/315; DOI : https://doi.org/10.4000/abpo. 315

Ce document a été généré automatiquement le 23 septembre 2020.

(c) Presses universitaires de Rennes 


\title{
Virginie Durand, Claude Ghiati, Isabelle Havelange et Brigitte Keriven, Bibliographie annuelle de l'histoire de France du $v^{e}$ siècle à 1958 - Année 2006
}

\author{
Bernard Merdrignac
}

\section{RÉFÉRENCE}

Paris, CNRS édition, 2007

1 Sous cette forme imprimée, la bibliographie pour l'année 2006 rendra aux historiens les services qu'ils sont en droit d'en attendre depuis plus d'un demi-siècle. Comme d'habitude, la recherche est facilitée par l'index chronologique, l'index des matières (incluant les anthroponymes et les toponymes), et la table des noms d'auteurs, ainsi que par la liste des périodiques et des Mélanges dépouillés. Son exhaustivité fait de l'ouvrage un instrument de travail sans équivalent parmi les grandes bibliographies internationales. D'autre part, les bases de données relatives au domaine historique français actuellement disponibles sur internet ne couvrent que des domain,es spécifiques (histoire des sciences, histoire de l'art, sciences des religions, etc.). Toutefois, le risque de marginalisation de cette bibliographie en fonction des nouvelles modalités de travail et de recherche de la communauté des historiens n'a pas échappé pas à l'équipe éditoriale. Conscientes de la nécessité de sa mise en ligne, les Auteurs font ici état de négociations en cours dont il faut espérer l'aboutissement prochain.

2 Cette livraison de l'année 2006 comporte 12323 références provenant du dépouillement systématique de 1216 revues françaises et 600 revues étrangères, depuis les Annales de l'Académie de Mâcon jusqu'à Zygon - Journal of Religion and Science (Chicago), auxquelles 
s'ajoutent 322 volumes de Mélanges et Actes de colloques (ainsi que des recensements ponctuels dans 55 autres revues françaises et 30 étrangères). Le volume apporte ainsi un témoignage de la vitalité du réseau de revues savantes, régionales ou locales, qui continue de remplir une fonction indispensable dans la diffusion par capillarité de la recherche historique en France. Les lecteurs des ABPO seront sans doute curieux d'apprendre qu'un récent sondage de la direction du CERHIO (Centre de Recherches Historiques de l'ouest - UMR CNRS 6258) a établi que les chercheurs de cette UMR publiaient dans plus de 200 revues différentes, ce qui ne va pas à l'encontre de cette constatation que l'on peut estimer réconfortante (même si cela soulève, par ailleurs, des problèmes de visibilité internationale).

3 Les tableaux statistiques qui, depuis 1997, ouvrent chaque livraison de la BAHF permettent de se faire une idée de l'évolution des champs d'intérêt de la production historique. Les auteurs font remarquer que durant le dernier demi-siècle (1955-2006) l'histoire politique se distingue par sa stabilité, tandis que l'histoire économique, l'histoire institutionnelle et l'histoire sociale (cette dernière surtout) font l'objet d'un intérêt croissant. Durant les cinq dernières années (2002-2006), la prédilection pour l'histoire politique de la IIIe République ne s'est pas démentie (en 2006, $28 \%$ des notices du chapitre $2:$ « Histoire politique»). Tous champs historiographiques confondus, cette période reste largement en tête des périodes étudiées (19,3\%), suivie par les décennies 1815-1851, puis par le XVIIIe et le XVII ${ }^{e}$ siècles. Le premier Empire est en hausse tandis que la IVe République accuse un léger recul. "Le Moyen Âge, le $\mathrm{xvI}^{\mathrm{e}}$ siècle, la Révolution, le second Empire et la Seconde Guerre mondiale demeurent stables ».

4 Comme le soulignent les A. dans leur "Avertissement liminaire ", ces statistiques font ressortir que l'un des traits les plus marquants de l'évolution de la discipline au cours des dernières décennies est la place croissante prise par l'«historiographie » dans le premier chapitre de l'ouvrage (« Manuels généraux et sciences auxiliaires de l'histoire »). De $9 \%$ du chapitre en 1960, celle-ci est passée à $30 \%$ en 2006, «que cette réflexion soit spontanée, du type "ego-histoire" ou suscitée par les attentes du corps social ». Tout se passe comme si l'" utilisation politique de l'histoire» (dans le cas par exemple des débats récents sur le rôle positif de la présence française outre-mer ou sur le rôle de la France dans la traite négrière) avait incité les chercheurs à approfondir leur réflexion sur les fonctions sociales de l'histoire. 